\title{
PREPARATION AND PROPERTIES OF A NEW THICK FILM SYSTEM
}

\author{
T. INOKUMA \\ Shoei Chemical Inc. 2-1-1, Nishi-Shinijuku, Shinijuku-ku, Tokyo, Japan
}

\author{
YOSHIAKI TAKETA and MIYOSHI HARADOME \\ Physical Science Laboratories, Nihon University 1-2-1, Izumi-cho, Narashino-shi, Chiba-ken, Japan
}

\begin{abstract}
Work has been carried out to develop a new ruthenium oxide based thick film resistor whose resistance is independent of the contact area of the conductor to the resistor. Such a resistor can then be combined with a low cost silver conductor.

It has been found that such a resistor can be made by doping a ruthenium oxide based thick film resistor with up to several percent of gold. With such a material it is possible to use silver or palladium silver (containing only very small amounts of palladium) as an electrode material and very few interactions have been found to occur between the resistor and electrode. Such a gold doped ruthenium oxide thick film resistor using silver electrodes has some major advantages as follows:-

1. The resistor size can be made much smaller than normal.

2. The design of a thick film hybrid circuit becomes easier.

3. The resistor cost can be reduced.
\end{abstract}

\section{INTRODUCTION}

Hybrid Integrated Circuits (HIC) are now being required with higher and higher integration densities and at the same time lower and lower costs. ${ }^{1-4}$ To satisfy such requirements, multilayer circuits and miniaturized electrical elements have had to be developed in order to obtain the necessary high packaging density.

Conductors that have as low a resistance as possible have had to be developed since the entire interconnection between the conductors and the other components for a multilayer HIC becomes relatively thin and long. ${ }^{5}$ When a thick film resistor is used for an electrical element for an HIC its length is often one $\mathrm{mm}$ or less. Often there is an appreciable difference between the sheet resistivity of such resistors, computed from devices with large aspect ratios (resistor length/width) to that found in practice for small aspect ratio resistors. This is because of the interaction that occurs at the interface between the electrode and the resistor in the firing process. ${ }^{6-8}$ Such a problem is one of the most serious obstacles to the design and production of satisfactory HICs. Furthermore, in all solutions to problems such as that stated above it is necessary to remember that one must try and utilize less expensive materials in order to lower the cost of HICs.

A large number of modern thick film circuits use palladium silver as the conductive material for the interconnections. It is desirable for the amount of palladium in the conductive material to be reduced in order to increase the conductivity and lower the price. However palladium silver conductors containing a small amount of palladium usually give rise to an interface problem between the conductor and resistors because of the firing process inducing the migration of silver into the resistor. ${ }^{1}$

In order to solve such problems a ruthenium oxide based thick film resistor has been developed that has a resistance independent of the contact area with the conductor.

Keywords: Ruthenium oxide TFR/silver electrodes 
TABLE I

Materials and compositions of the samples.

\begin{tabular}{lll}
\hline Sample & Materials & Composition \\
\hline Resistor A (R-A) & $\mathrm{RuO}_{2}+$ Glass & $\mathrm{RuO}_{2} / \mathrm{Glass}=20 / 80$ \\
Resistor B (R-B) & $\mathrm{RuO}_{2}+$ Glass $+\mathrm{Au}$ & $\mathrm{RuO}_{2} / \mathrm{Glass}=20 / 80+2 \mathrm{wt} \% \mathrm{Au}$ \\
Resistor C (R-C) & $\mathrm{RuO}_{2}+$ Glass $+\mathrm{Au}$ & $\mathrm{RuO}_{2} / \mathrm{Glass}=20 / 80+4 \mathrm{wt} \% \mathrm{Au}$ \\
Conductor $(\mathrm{Ag})$ & $\mathrm{Ag}+$ Glass & $\mathrm{Ag} / \mathrm{Glass}=96 / 4$ \\
Standard Conductor $(\mathrm{PtAu})$ & $\mathrm{Pt}+\mathrm{Au}+$ Glass & $\mathrm{Pt} / \mathrm{Au} / \mathrm{Glass}=75 / 22 / 3$ \\
\hline
\end{tabular}

(i.e. independent of the aspect ratio, $1 / \mathrm{w}$ ). Such a resistor exhibits no mutual diffusion between the conductor and the resistor and thus allows of a situation in which a ruthenium oxide based thick film resistor can be combined with a cheap silver thick film conductor.

It has subsequently been found that a palladium silver thick film containing only a small amount of palladium, or even a conductor containing only silver, can be used to contact a ruthenium oxide thick film resistor, providing the thick film resistor contains a small amount of gold.

\section{SAMPLES}

Samples used in the experiments are listed in Table I. Figure 1 shows the sheet resistivities of the samples with the various aspect ratios, $1 / \mathrm{w}$, ranging from 0.5 through to 4. Curve D is a typical result obtained using an expensive gold platinum thick film

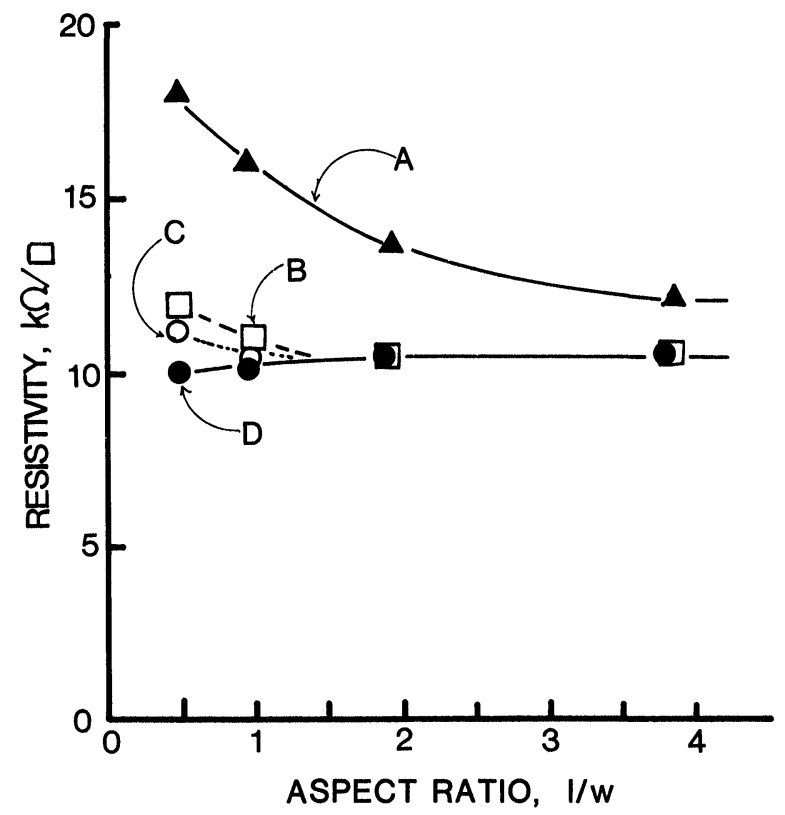

FIGURE 1 Aspect ratio versus sheet resistivity. $\mathrm{A} \mathrm{RuO}_{2} / \mathrm{Ag}, \mathrm{B} \mathrm{RuO} \mathrm{R}_{2}+2 \% \mathrm{Au} / \mathrm{Ag}, \mathrm{C} \mathrm{RuO}_{2}+4 \% \mathrm{Au} / \mathrm{Ag}$, $\mathrm{D} \mathrm{RuO} / \mathrm{AuPt}$. 
conductor together with the different resistive materials. It can be seen that with this conductor the resistance obtained is independent of the aspect ratio, 1/w. It was therefore used as a reference electrode for the whole of the experiment.

Resistor samples with width of $1 \mathrm{~mm}$, had length varying from $0.5 \mathrm{~mm}$ to $4 \mathrm{~mm}$. The overlap between the conductors and the resistors was set at $0.3 \mathrm{~mm}$. The average fired film thickness of both the conductors and the resistors was fixed at 12 microns.

\section{EXPERIMENTS AND RESULTS}

Results for the various materials discussed in Table I are shown in Figure 1. Aspect ratios ranging from 0.5 through to 4 were used. For resistor type A (plain ruthenium oxide) using a silver conductor, it is seen that the sheet resistivity changes as the aspect ratio varies. On the contrary, for resistor type $\mathrm{B}$ (ruthenium oxide plus $2 \%$ gold) and resistor type $\mathrm{C}$ (ruthenium oxide plus $4 \%$ gold), the sheet resistivities become almost independent of the ratio $1 / \mathrm{w}$. It is found that a $4 \%$ addition of gold to the ruthenium oxide is the most effective. Higher percentages of gold cause the resistivity to become unacceptably low.

The sheet resistivities obtained with an aspect ratio of 0.5 are greater than those obtained at an aspect ratio of 4 because of the migration of the silver conductor. This phenomena has been examined by measurement of the surface electric potential distribution which allows one to determine how far migration has propagated into the resistor. As shown in Figure 2 silver can migrate into the resistor up to approximately $0.4 \mathrm{~mm}$.

From Figure 2 one would expect that resistors longer than $0.5 \mathrm{~mm}$ will not be affected by migration of silver from the silver conductors. Therefore the resistivity of each part of a resistor, separated by an interval of $1 \mathrm{~mm}$, has been measured, and Figure 3 is a diagram detailing the areas investigated. Figures 3(a), (b) and (c) refer to samples with an aspect ratio of 4 . Four different resistance areas can be distinguished and these are defined as $\mathrm{P}_{1}, \mathrm{P}_{2}, \mathrm{P}_{3}$ and $\mathrm{P}_{4}$. Only regions $\mathrm{P}_{1}$ and $\mathrm{P}_{4}$ are those affected by the silver

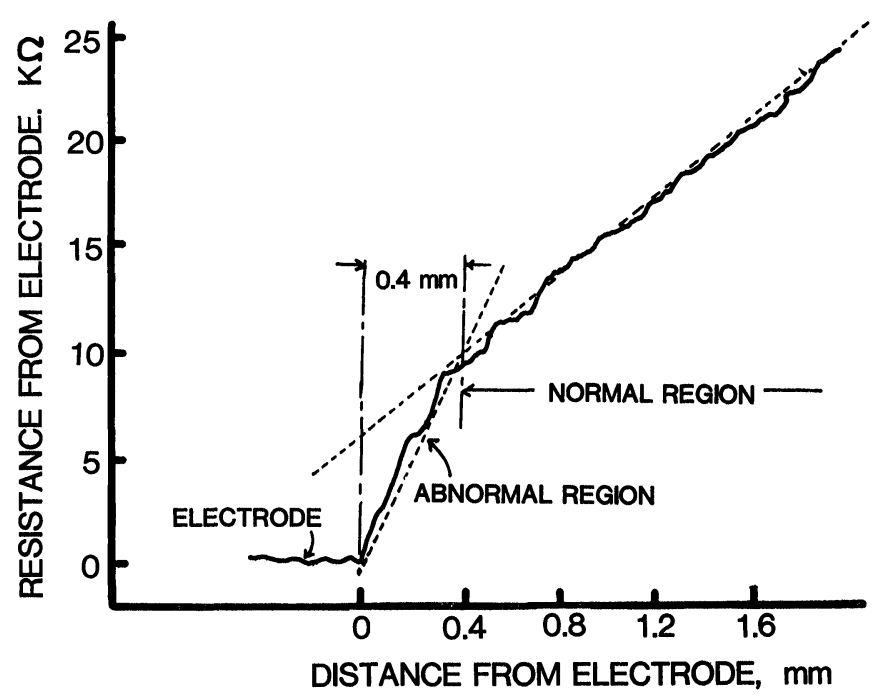

FIGURE 2 Surface potential distribution of sample. 
(a)

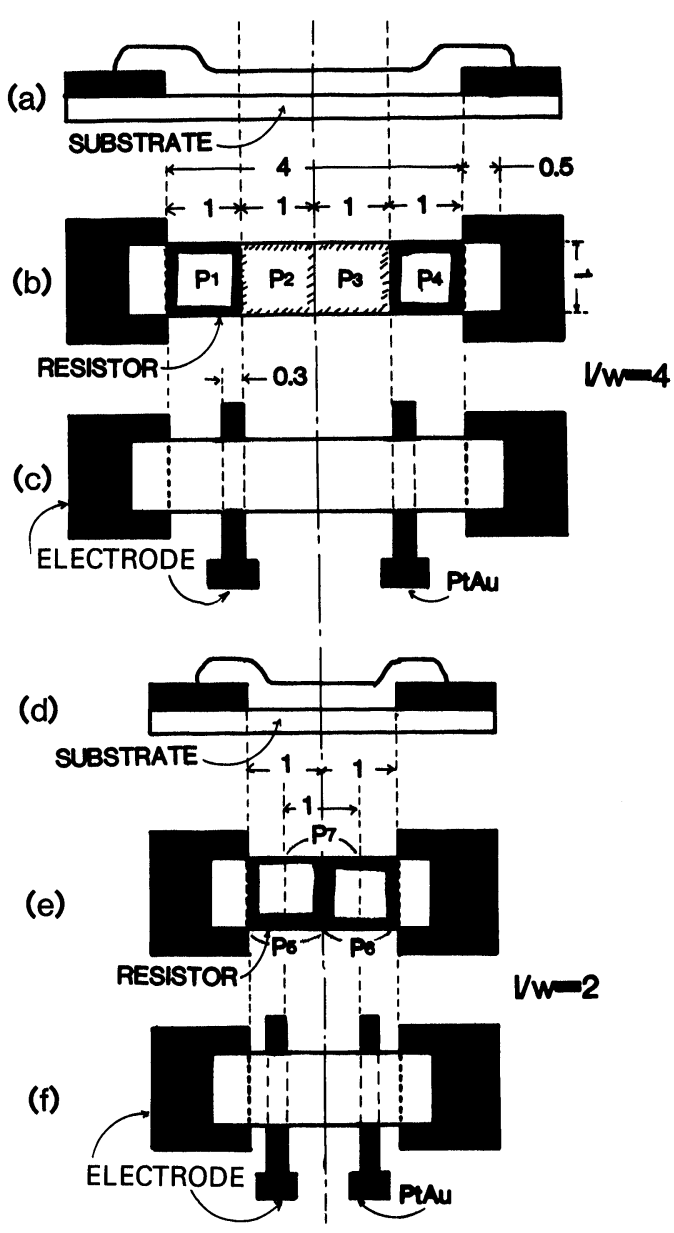

FIGURE 3 Diagram of material distribution on resistors with $\mathrm{Ag}$ conductor connections. 3(a), (b) and (c) - Aspect ratio 4:1; 3(d), (e) and (f) - Aspect ratio 2:1.

migration. Figures 3(d), (e) and (f) refer to resistors with an aspect ratio of 2 . In this case different resistor areas $\mathrm{P}_{5}, \mathrm{P}_{6}$, and $\mathrm{P}_{7}$ can be distinguished, with areas $\mathrm{P}_{5}$ and $\mathrm{P}_{6}$ being similar to $\mathrm{P}_{1}$ and $\mathrm{P}_{4}$ in Figure $3(\mathrm{~b})$.

From measurements of resistors with aspect ratios of 4 it can be shown that the sheet resistivity of the unaffected portions of the resistor $\left(\mathrm{P}_{2}, \mathrm{P}_{3}\right)$ is $10.6 \mathrm{~K} \mathrm{ohms} / \mathrm{sq}$. Similarly it can be shown that when the aspect ratio is 2 , the sheet resistivity of $P_{7}$, again an unaffected part of the resistor, is $10.7 \mathrm{~K}$ ohms.

In order to avoid the effect of the conductor contact and to obtain the real resistivity of the sample, contact electrodes to the resistors were prepared using platinum gold resin conductors with a width of $0.3 \mathrm{~mm}$, as shown in Figures 3(c) and 3(f). Using this technique the resistivity between the platinum silver electrodes was found to give $10.6 \mathrm{~K}$ $\mathrm{ohms} / \mathrm{sq}$. It was by using techniques such as this, that it was found that no effect was obtained from silver migration at distances greater than $0.5 \mathrm{~mm}$ away from the conductor contact. 
TABLE II

Resistivity of different sections of resistors using doped $\mathrm{RuO}_{2}$ (see Figure 3 for definition of areas)

\begin{tabular}{lll}
\hline Sample & Resistance of $P_{1}$ or $P_{4}(\mathrm{k} \Omega /)$ & Resistance of $P_{2}$ or $P_{3}(k \Omega /)$ \\
\hline $2 w t \%$ doped R-B & 11 & 10.5 \\
$4 \mathrm{wt} \%$ doped R-C & 10.8 & 10.3 \\
\hline
\end{tabular}

In order to attempt to eliminate the high resistivity region obtained in the vicinity of the conductor contact, various experimental possibilities have been tried.

These are:-

1. Changing the firing conditions of both the conductors and the resistors.

2. Adding various dopants, except palladium, to silver conductors.

3. Adding various dopants to the resistors.

As a result it was found that the abnormal resistivity region in the vicinity of the conductor contacts was removed if gold was added to the resistors and this did not change any other physical or electrical property.

Results of such experiments have already been discussed in Table I and Figure 1. Furthermore the sheet resistivities found in Figure $3(\mathrm{~b}), \mathbf{P}_{1}, \mathrm{P}_{2}, \mathrm{P}_{3}$, and $\mathrm{P}_{4}$, were examined for the aspect ratio, $1 / \mathrm{w}=4$. The results are shown in Table II. It can be seen
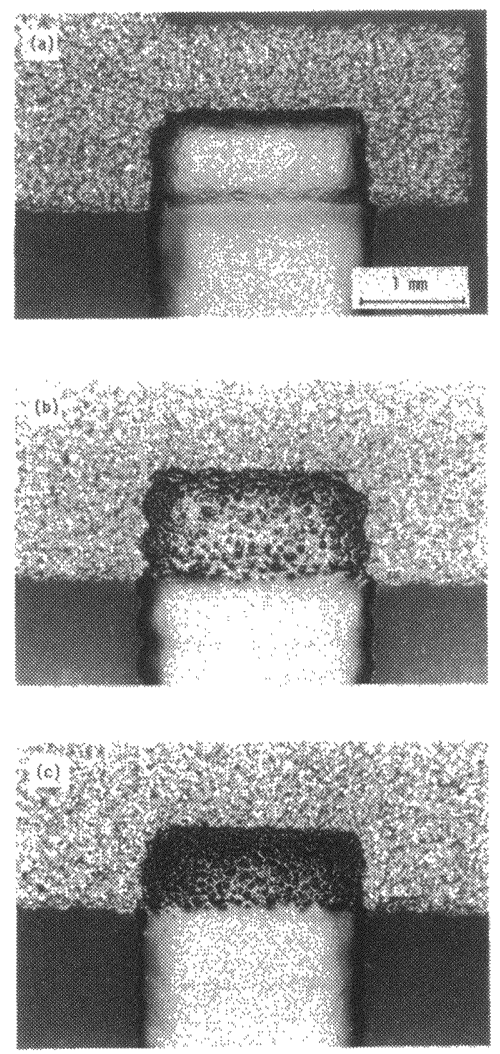

FIGURE 4 Optical micrographs of conductor - resistor overlap areas. (a) $\mathrm{Ag} / \mathrm{RuO}_{2}$, (b) $\mathrm{Ag} / \mathrm{RuO}_{2}+2 \% \mathrm{Au}$, (c) $\mathrm{Ag} / \mathrm{RuO}_{2}+4 \% \mathrm{Au}$. 
there is hardly any difference between the resistivities of the four sections. This further confirms that gold doped ruthenium oxide thick film resistors are not affected by silver conductor contacts and, therefore, that the amount of palladium in palladium silver conductors can be reduced. This will not only reduce the resistivity of the conducting material but will also allow of the use of a cheaper material.

Ageing tests on gold doped ruthenium oxide resistors using silver conductor contacts has shown that the change in electrical properties is minimal.

Studies have been made on whether or not there is any physical or chemical change that would occur in gold doped ruthenium oxide resistors. Figure 4 is a micrograph obtained in the vicinity of the overlapping section between the conductor contact and the resistor. For resistor type A the interface appears to be smooth and glassy as shown in Figure 4(a). In Figures 4(b) and 4(c) are shown the overlapping surfaces for resistors type B and type C. Many protuberances are visible on the overlapping surfaces. Figure $5(\mathrm{a}-\mathrm{d})$ are the sections obtained using an X-ray microanalyser. The sample has been taken from the interfacial portion of a silver conductor which has been covered by a gold-containing ruthenium oxide resistor. Silver can be seen to have penetrated through the ruthenium oxide layer to protrude on to the surface. Gold has also been found to be presenst in the protuberances. This distribution of elements is summarized in the sketch of Figure 5(e). The protuberances are seen to be a solid solution that contains silver produced from the conductor material and gold produced from the
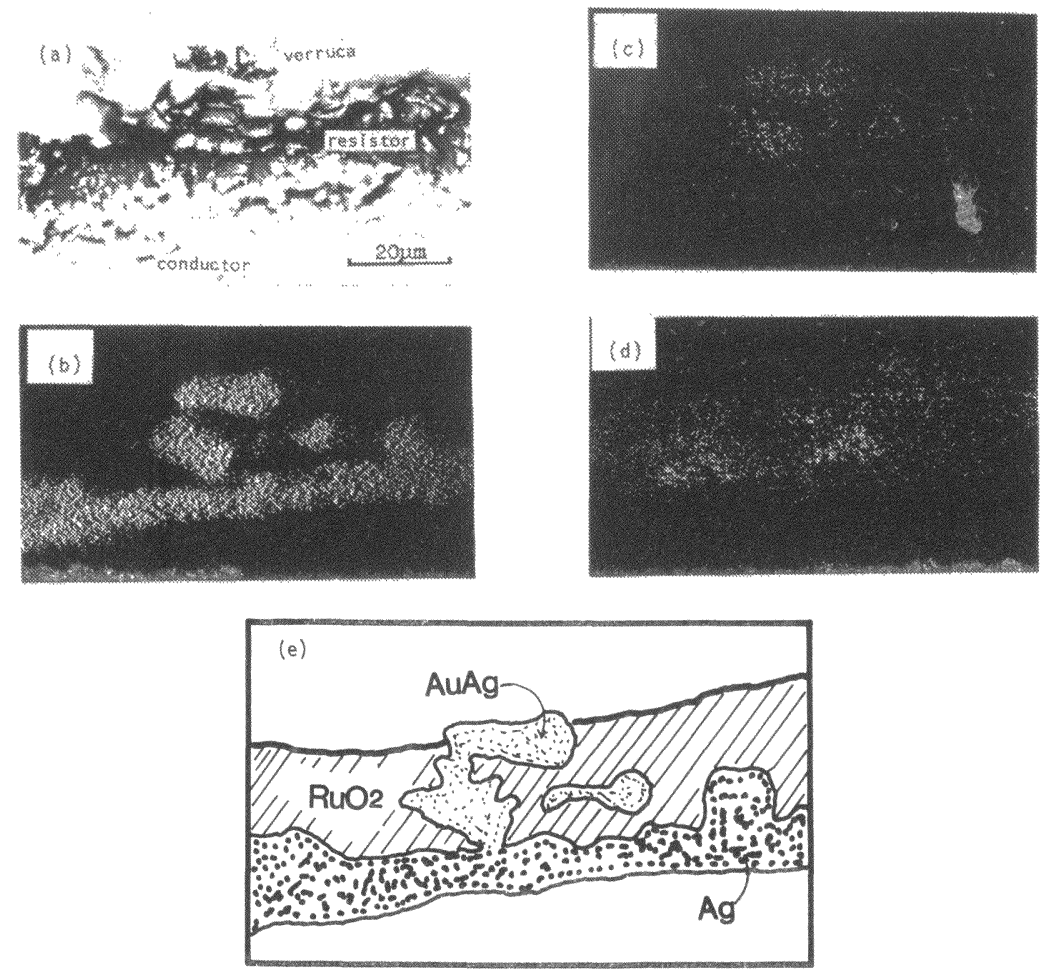

FIGURE 5 X-ray microanalysis. (a) cross section view of the sample, (b) Ag distribution, (c) Au distribution, (d) Ru distribution, (e) Analytical sketch. 


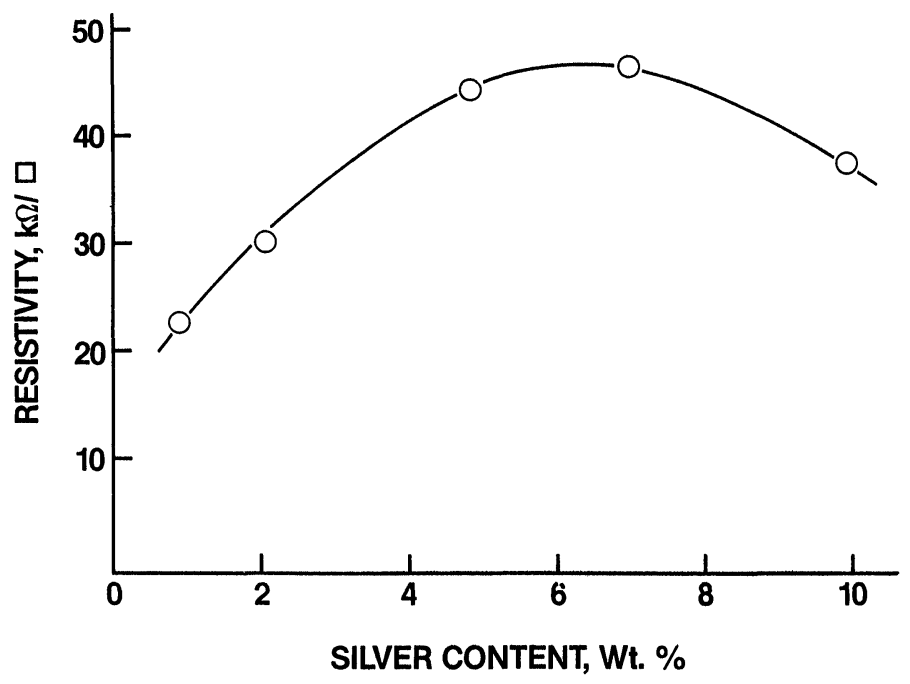

FIGURE 6 Silver content versus sheet resistivity. $\mathrm{RuO}_{2} / \mathrm{Glass}=20 / 80$, Conductor: Silver, Resistor geometry: $1 \mathrm{~mm}(\mathrm{w}) \times 2 \mathrm{~mm}(1)$

resistors. A similar phenomena has been observed in the case of silver/palladium conductors when the addition of palladium is very small. Silver diffuses into the resistor during firing, which increases the resistivity of the resistor in the vicinity of the conductor. Therefore, the relationship between resistivity and the amount of silver added to the ruthenium oxide based resistor has been investigated. The results are shown in Figure 6. Resistivity increases until the silver amounts to $7 \mathrm{wt} \%$ of (ruthenium oxide + glass) weight. When the silver content exceeds $7 \%$, large particles of silver are formed in the resistor and as a result the resistivity begins to decline.

In order to understand the relationship between the silver conductors and the gold dispersion within the resistors, samples have been prepared in which the ruthenium oxide has been replaced by undoped glass or by glass containing a small addition of gold. (4\% gold in glass). These materials have been fired onto previously prepared silver conductors. The resultant cross sections through the interfaces obtained are shown in Figure 7. From the micrographs obtained at the junctions between the silver conductor and gold doped glass, it can be seen that silver grows into the gold doped glass region in a dendritic manner [Figures 7(b) and 7(d)]. The silver dendrites dissolve the gold in the glass and build up a solid solution growing into large particles. However, for the silver conductor glass interface it can be seen from Figures 7(a) and 7(c) that such a phenomena does not occur.

\section{CONCLUSIONS}

It has been shown that ruthenium oxide based thick film resistors can be prepared containing up to $4 \%$ of gold. Such resistors can be used satisfactorily on top of silver conductor contacts without any migration of silver into the resistive part of the resistor. A similar situation has been found using palladium silver conductor contacts provided the amount of palladium is very small. Microscopic evidence has shown it is the presence of gold in the resistors that determines the diffusion of silver into the resistor body. 

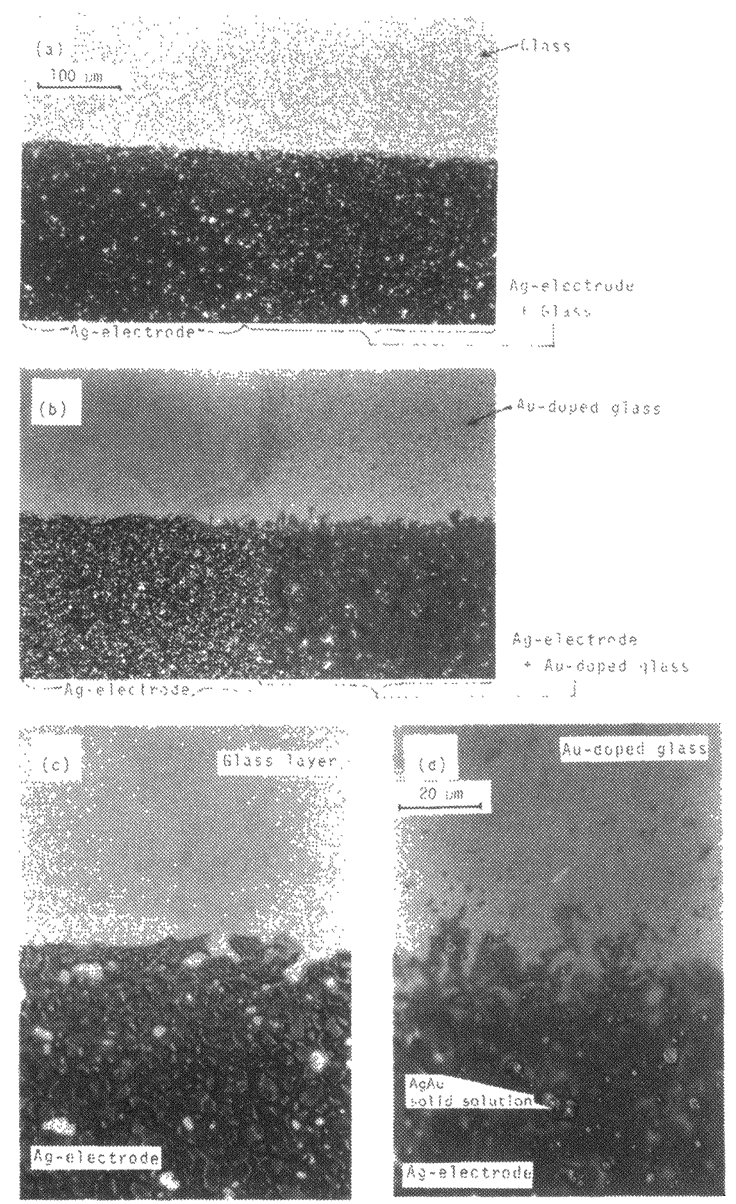

FIGURE 7 Micrographs of interface region of, (a) and (c), Ag conductor-undoped glass; (b) and (d), Ag conductor-Au doped glass.

Since the percentage of palladium in palladium silver conductors can be reduced in gold doped ruthenium oxide resistors are used, this has meant that the resistivity of the conductor can be decreased, migration of silver along the resistor can be eliminated and finally that the cost of the conductor material can be considerably reduced.

\section{REFERENCES}

1. R.D. Jones, “Hybrid Circuit Design and Manufacture”, Marcel Dekker, Inc. (1982).

2. D.E. Riemer, Electric Comp. Conf. p. 102 (1970).

3. Electric Comp. Conf., p. 209 (1970).

4. P.E. Pogren, Proc. 1977 International Microelectronics Symposium, p. 267 (1976)

5. Editing by Japan Microelectronics Society: "Astumaku IC-ka Gijutsu”, Kogyochoshakai Inc. (1983).

6. C.Y. Kuo, Proc. 1969 Hybrid Microelectronics Symp. p. 263 (1969)

7. J.B. Garvin and S.J. Stein, Proc. 1970 20th Electronic Components Conference, p 190 (1970).

8. J.A. Loughrun and R.A. Sigsbee, Proc. 1969 Hybrid Microelectronics Symp. p 271 (1969). 

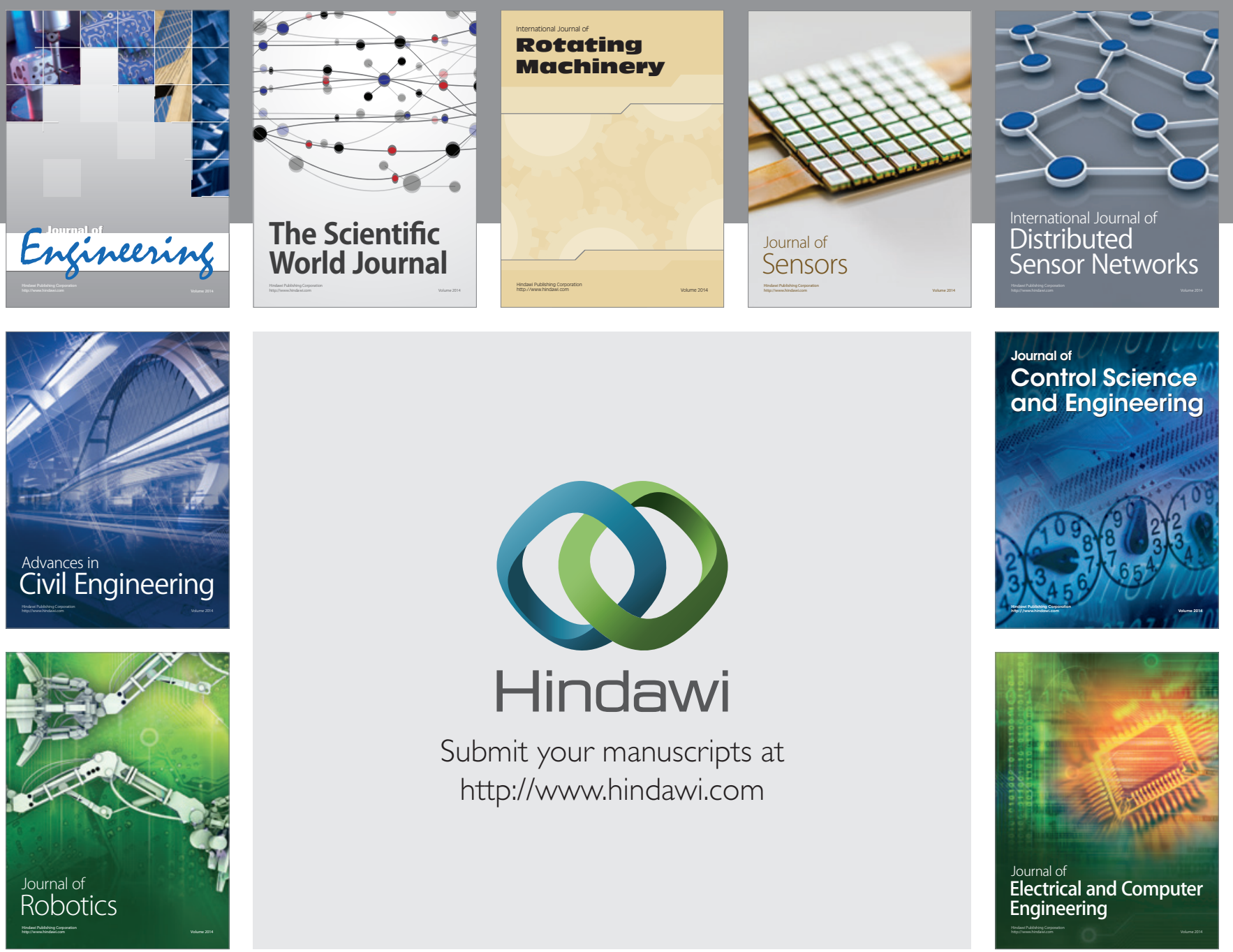

Submit your manuscripts at

http://www.hindawi.com
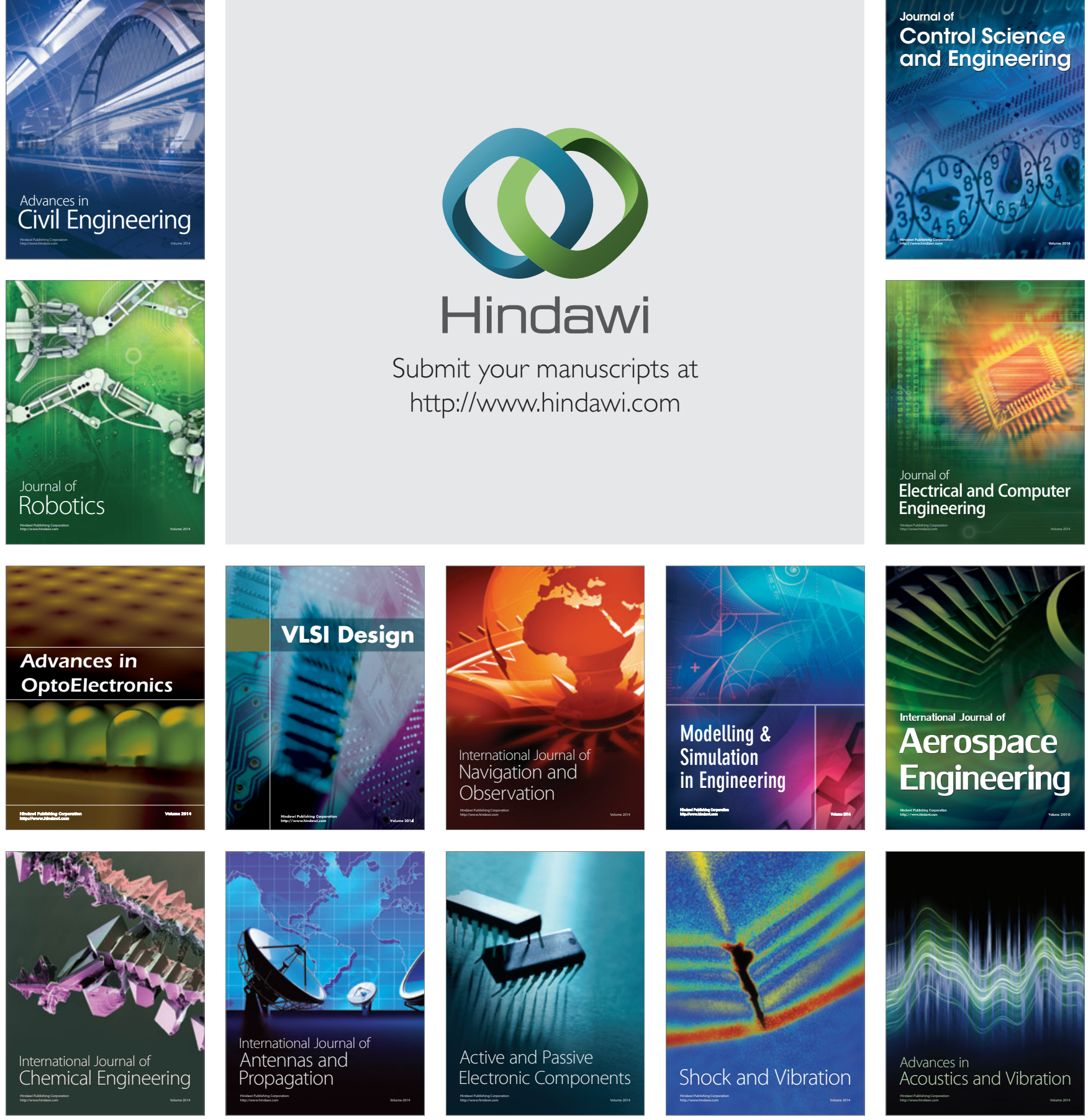